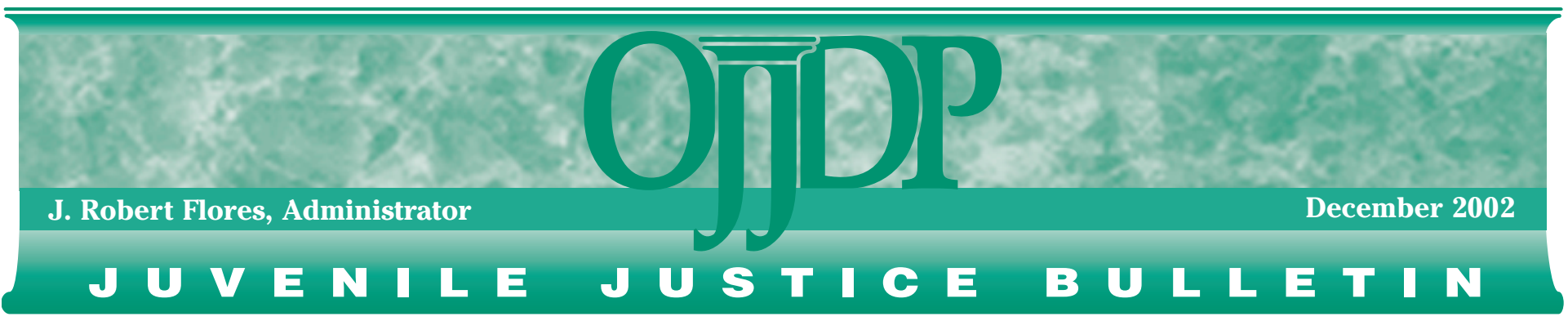

\section{Violent Victimization as a Risk Factor for Violent Offending Among Juveniles}

\section{Jennifer N. Shaffer and R. Barry Ruback}

As a group, juveniles have high rates of violent victimization and violent offending, a pattern suggesting that some juveniles are both victims and perpetrators of violence. To explore that hypothesis, this Bulletin analyzes the relationships between violent victimization and violent offending across a 2-year period, using data for 5,003 juveniles who participated in the National Longitudinal Study of Adolescent Health. The Bulletin looks at victimization and offending experiences in subgroups of juveniles classified by age, gender, race, and level of physical development. It also identifies risk and protective factors for victimization and offending. Key conclusions and policy implications include the following:

- Violent victimization is indeed a warning signal for future violent offending among juveniles. Protecting juveniles against violent victimization may, therefore, reduce overall levels of juvenile violence.

- Because some groups are at higher risk than others for violent victimization, policies and programs aimed at preventing victimization may be most effective if they are focused on these groups.

$\checkmark$ Violent victimization and violent offending share many of the same risk factors, and many of these risk factors suggest opportunities for intervention.

The Bulletin includes background information, a brief theoretical discussion, study methods and findings, conclusions, policy implications, and suggestions for future research.

\section{Background}

Statistical evidence suggests disproportionately high rates of violence by and against juveniles. This evidence comes both from surveys that ask about behaviors and victimization experiences and from official records.

Surveys of self-reported behaviors of adolescents and young adults indicate high rates of offending among these age groups (Elliott et al., 1983; Lauritsen, Sampson, and Laub, 1991). Similarly, surveys of victims' perceptions of offender characteristics indicate that the most common age group for offenders committing rape, robbery, and assault is youth ages 18-20, followed by juveniles ages 15-17 (Hindelang, 1981). Furthermore, Uniform Crime Report data show that arrest rates for murder, forcible rape, robbery, and aggravated assault are higher for older teens than for

\section{A Message From OJJDP}

Compared with adults, juveniles are disproportionately affected by high rates of violence as both offenders and victims. Understanding the relationship between victimization and offending is therefore of critical importance.

Examining data from the National Longitudinal Study of Adolescent Health, the authors of this Bulletin found that victims of violence were significantly more likely than nonvictims to become violent offenders. They also found that violent victimization and violent offending share many of the same risk factors, such as previous violent victimization and offending, drug and alcohol use, and depression. These findings are particularly important because they suggest that interventions directed at preventing victimization could also reduce offending, and vice versa.

The analysis presented in this Bulletin provides evidence that peers and adults can and do play important roles in the lives of juveniles. Juveniles who said that they had support from friends, parents, teachers, and others were less likely to commit a violent offense. These findings underscore the need for and value of mentoring, parenting, and anger management programs that provide opportunities for juveniles to interact with caring adults. By identifying youth who are most at risk and examining the links between victimization and offending, we can improve our ability to intervene positively in these juveniles' lives. 
any other age group (Federal Bureau of Investigation, 2000).

When asked about their victimization experiences in the previous year, 18 percent of a large national sample of 8th, 10th, and 12th grade students said they had been injured by an attacker who did not use a weapon, and 5 percent said they had been injured by an attacker with a weapon (Johnston, Bachman, and O'Malley, 2001). Rates of serious violent victimization are twice as high for juveniles ages $12-17$ as for adults age 18 or older, and rates of simple assault victimization are three times higher (Snyder and Sickmund, 1999).

\section{Theoretical Perspective}

According to both lifestyle exposure theory and routine activities theory (Hindelang, Gottfredson, and Garofalo, 1978; Cohen and Felson, 1979), individuals' risk of criminal victimization depends on their exposure or proximity to offender populations, and exposure, in turn, depends on individuals' lifestyles and routine activities. Because individuals are most likely to interact with those who are similar to themselves, individuals' victimization risk is directly proportional to the number of characteristics they share with offenders (Hindelang, Gottfredson, and Garofalo, 1978). That is, offenders are more likely than nonoffenders to become victims, because their lifestyles frequently bring them in contact with other offenders. Offenders are also more likely than nonoffenders to use alcohol or illegal drugs, which lowers their ability to protect themselves and their property, and to live in neighborhoods characterized by high levels of population mobility, heterogeneity, and social disadvantage (e.g., poverty and unemployment), which increases their exposure to other offenders (Sampson and Lauritsen, 1994).

Offenders are also likely to be attractive targets for crime because they can be victimized with little chance of legal consequences (Sparks, 1982). Offenders are probably less likely than nonoffenders to report victimization to the police because they do not want to draw attention to their own illegal behavior (e.g., starting the altercation in question or carrying illegal drugs) and because, if they do file a report, the police probably perceive them as less credible than nonoffenders. Offenders' reluctance to report their own victimization might be especially true for violent juvenile offenders, because juveniles in general are less likely than adults to report violent victimization to the police (Finkelhor and Ormrod, 1999).

Research findings are consistent with these theoretical reasons for expecting that the same individuals are often both victims and offenders. Studies using British Crime Survey data have found a strong positive association between offending and personal victimization among adults (Hough and Mayhew, 1983; Sampson and Lauritsen, 1990). Studies of juveniles in the United States also show that the individuals most likely to be victims of personal crime are those who report the greatest involvement in delinquent activities (Lauritsen, Sampson, and Laub, 1991). In addition, the greater the variety of delinquent activities, the greater the risk of victimization (e.g., Jensen and Brownfield, 1986; Esbensen and Huizinga, 1991; Lauritsen, Sampson, and Laub, 1991).

\section{Data and Methods}

Although earlier studies suggest that criminal victimization and criminal offending are related, the nature of the relationship is ambiguous. The present study investigates the nature of the relationship in a sample of juveniles ages 11-17, addressing three issues:

- How are violent victimization and violent offending related over time? Does prior victimization predict subsequent offending, does prior offending predict subsequent victimization, or do they both predict each other? In particular, is victimization a significant risk factor for subsequent offending?

- What individual-level factors might explain the relationship between victimization and offending? Do the same factors predict both violent victimization and violent offending?

$\checkmark$ Does drug use affect the relationship between victimization and offending?

The study focuses on violence among juveniles for three reasons. First, from a policy standpoint, it makes sense to concentrate on the most serious offenses, particularly since less is known about the violent victimization of juveniles than about the violent victimization of adults. Second, because many fewer juveniles engage in violence than in property offending and in minor deviant acts, it would be easier to target interventions at this smaller group. Third, the data source for the analyses in this Bulletin included measures of nonviolent offending but not of nonviolent victimization.

\section{Data Source}

The findings reported in this Bulletin are based on statistical analyses of the restricted-access contractual dataset from the first two waves of the National Longitudinal Study of Adolescent Health (known as the Add Health Study), which is a longitudinal study of a representative national sample of juveniles in grades 7 through $12 .{ }^{1}$ The study used a clustered sampling design based on a stratified sample of 80 high schools and 52 paired middle schools. ${ }^{2}$ Students in these 132 schools were asked to complete an in-school questionnaire. In addition, a subsample, stratified by grade and gender, was selected for in-home interviews, which included information about family composition and dynamics, substance use, criminal and delinquent activities, and violent victimization. The in-home interviews, which were conducted in 1995 (year 1) and again in 1996 (year 2), are the basis for the analyses in this Bulletin.

The analyses reflect interview data for 5,003 juveniles: 2,402 males and 2,601 females; 2,768 non-Hispanic white juveniles and 2,235 minority juveniles $;^{3} 1,147$ juveniles ages $11-14$ and 3,856 ages $15-17$ at the time of the second interview. The analyses exclude respondents who did not have complete data for all of the variables included in the analyses, those whose second interview was conducted less than 11 months after their first interview, ${ }^{4}$ and those who were age 18 or older at the time of the second interview. ${ }^{5}$

\section{Analytical Approach}

First, the sample is described in terms of the percentages who reported violent victimization, violent offending, and both victimization and offending, in year 1 , year 2, and both years; and the links between victimization and offending within each year are summarized. Next, relationships between violent victimization and violent offending over time are examined-i.e., between victimization in year 1 and victimization in year 2, offending in year 1 and victimization in year 2 , victimization in year 1 and offending in year 2, and offending in year 1 and offending in year 2-for the sample as a whole and for subgroups based on demographic characteristics (age, gender, and race) and level of physical development. Finally, through multivariate analyses, the effect of drug use on these relationships is investigated, and risk and protective factors associated with victimization and offending are explored. ${ }^{6}$ 


\section{Measures}

The measures of offending and victimization used in the analyses were dichotomous measures based on juveniles' yes/ no responses to multiple items. ${ }^{7}$ Two sets of measures were used, reflecting the two waves of data (i.e., years 1 and 2). The measures of violent offending included five items reflecting serious physical offenses against other persons

- Got into a serious physical fight.

- Hurt someone badly enough to need bandages or care from a doctor or nurse.

$\checkmark$ Used or threatened to use a weapon to get something from someone.

- Shot or stabbed someone.

- Pulled a knife or gun on someone.

The measures of violent victimization included four items reflecting serious physical violence:

$\checkmark$ Someone pulled a knife or gun on you.

- You were shot.

- You were cut or stabbed.

- You were jumped.

Juveniles were categorized as offenders if they reported committing any of the listed offenses and as nonoffenders if they reported not committing any of these offenses. Juveniles were similarly categorized as victims or nonvictims, based on whether they reported having any of the listed acts committed against them.

Juveniles were also categorized on the basis of their reports of using any one of the following drugs:

- Marijuana.

- Cocaine.

$\checkmark$ Inhalants.

$\checkmark$ Other drugs, including LSD, PCP, ecstasy, ice (crystal methamphetamine), heroin, mushrooms, speed (amphetamines), or pills without a doctor's prescription.

Juveniles were categorized into one of four groups: nonusers (no reported use of any drug at either of the two interviews), desisters (reported use at first interview but not at the second interview), new users (reported use at the second interview but not the first), and consistent users (reported use at both interviews). Juveniles were similarly categorized on the basis of reported alcohol use.

\section{Findings}

\section{Incidence}

As indicated in table 1, the percentages of offenders and victims were high in years 1 and 2. Forty percent of juveniles reported violent offending in year 1, 23 percent in year 2 , and 17 percent in both years. Nineteen percent reported violent victimization in year 1,15 percent in year 2 , and 9 percent in both years. Fifteen percent of juveniles reported both committing and being the victim of a violent crime in year 1,10 percent in year 2, and 6 percent in both years. Generally, the percentages of juveniles reporting offending and victimization were greater in year 1 than in year 2 . This decline is likely related to "telescoping," or the tendency of survey respondents to report events that occurred outside the time period about which they were asked (in this study, prior to year 1). ${ }^{8}$

\section{Table 1: Incidence of Violent Offending and Violent Victimization}

\begin{tabular}{lccc} 
& \multicolumn{3}{c}{ Percentage of Juveniles Reporting* } \\
\cline { 2 - 4 } Year & $\begin{array}{c}\text { Violent } \\
\text { Offending }\end{array}$ & $\begin{array}{c}\text { Violent } \\
\text { Victimization }\end{array}$ & $\begin{array}{c}\text { Both Offending } \\
\text { and Victimization }\end{array}$ \\
\hline Year 1 & 40 & 19 & 15 \\
Year 2 & 23 & 15 & 10 \\
Both years & 17 & 9 & 6
\end{tabular}

* Sample size $=5,003$.

Table 2: Relationship Between Violent Offending and Violent Victimization Within Years: Total Sample

Year 1

\begin{tabular}{lcc} 
Status in Year 1 & Violent Offending (\%) & Violent Victimization (\%) \\
\hline All $(N=5,003)$ & 40 & 19 \\
Offender & 100 & 37 \\
Nonoffender & 0 & 7 \\
Victim & 78 & 100 \\
Nonvictim & 32 & 0
\end{tabular}

Year 2

Status in Year 2

Violent Offending (\%) Violent Victimization (\%)

\begin{tabular}{lcc} 
& \multicolumn{2}{c}{ Year 2 } \\
\cline { 2 - 3 } Status in Year 2 & Violent Offending (\%) & Violent Victimization (\%) \\
\hline All $(N=5,003)$ & 23 & 15 \\
Offender & 100 & 42 \\
Nonoffender & 0 & 7 \\
Victim & 66 & 100 \\
Nonvictim & 16 & 0
\end{tabular}

As shown in table 2, there was a strong , juveniles who offended were 5.3 times who were victimized were 2.4 times who were victimized were 4 times more mind that, although data indicate a close temporal proximity ordering of events within a year-i.e., a particular youth first was victimized and then offended, or vice versacannot be determined from the data. of offending and victimization, temporal 


\section{Key Findings}

- Juveniles who were victims of violence in year 1 were significantly more likely than nonvictims to commit a violent offense in year 2 and to be victims of violence in year 2 .

- Juveniles who committed a violent offense in year 1 were significantly more likely than nonoffenders to commit a violent offense in year 2 and to be victims of violence in year 2.

$\checkmark$ In general, these patterns were true regardless of age, gender, race, level of physical development, or drug use.

Because of this limitation, the rest of the analyses presented in this Bulletin will focus on the relationships between violent victimization and offending across years.

\section{Relationships Among Variables}

The data in tables 3-7 indicate relationships between violent offending and violent victimization across years. Table 3 shows these relationships for the total sample. Tables 4-7 show the relationships by age group, gender, race, and level of physical development. In the discussion that follows, all references to "significant" differences in respondents' likelihood of offending or victimization (i.e., differences between percentages reported in the tables) refer to differences that are statistically significant at the $p<.05$ level, based on standard chi-square tests. Readers should use caution when comparing estimates not explicitly discussed in the text; what may appear to be a large difference may not be a statistically significant difference.

Total sample. Table 3 shows that, in the total sample of 5,003 juveniles, those who committed a violent offense or were victims of violence in year 1 had a significantly increased likelihood of offending or being victimized in year 2. Juveniles who offended in year 1 were 4.4 times more likely than nonoffenders to offend in year 2 (44 percent versus 10 percent) and 4.7 times more likely to be victimized in year 2 (28 percent versus 6 percent). Juveniles who were victimized in year 1 were 3 times more likely than nonvictims to offend in year 2 (52 percent versus 17 percent) and 6 times more likely to be victimized in year 2 (47 percent versus 8 percent).
By age. Juveniles were divided into two groups according to their age in year 2 : 11-14 and 15-17. As shown in table 4, the total percentage of juveniles who were victims of violence in year 2 was significantly greater for the older group; however, there was no significant difference between the two age groups in the percentages who committed a violent offense in year 2 . For both age groups, juveniles who offended in year 1 were significantly more likely than nonoffenders to be victimized in year 2 , and those who were victimized in year 1 were significantly more likely than nonvictims to offend in year 2 . These findings are consistent with the pattern for all juveniles.

By gender. As shown in table 5, males were significantly more likely than females to commit a violent offense in year 2 and to be victims of violence in year 2 . For both males and females, juveniles who offended in year 1 were significantly more likely than nonoffenders to be victimized in year 2 , and those who were victimized in year 1 were significantly more likely than nonvictims to offend in year 2. Again, these findings are consistent with the pattern for all juveniles.

By race. The data were analyzed separately for white and minority juveniles (see endnote 3 for racial groups included in the minority category). As indicated in table 6, both the total percentage of juveniles who committed a violent offense in year 2 and the total percentage who were victims of violence in year 2 were greater for the minority category. For both minorities and

\section{Table 3: Relationship Between Violent Offending and Violent Victimization Across Years: Total Sample}

\begin{tabular}{lcc} 
& \multicolumn{2}{c}{ Year 2 } \\
\cline { 2 - 3 } Status in Year 1 & Violent Offending (\%) & Violent Victimization (\%) \\
\hline All $(N=5,003)$ & 23 & 15 \\
Offender & 44 & 28 \\
Nonoffender & 10 & 6 \\
Victim & 52 & 47 \\
Nonvictim & 17 & 8
\end{tabular}

\section{Table 4: Relationship Between Violent Offending and Violent Victimization Across Years, by Age Group}

Year 2

\begin{tabular}{lcr} 
Status in Year 1 & Violent Offending (\%) & Violent Victimiz \\
\hline Ages 11-14 & & \\
All (n=1,147) & 23 & 13 \\
$\quad$ Offender & 42 & 23 \\
$\quad$ Nonoffender & 12 & 6 \\
$\quad$ Victim & 56 & 37 \\
$\quad$ Nonvictim & 18 & 8 \\
Ages 15-17 & & \\
All (n=3,856) & 22 & 16 \\
$\quad$ Offender & 45 & 30 \\
$\quad$ Nonoffender & 9 & 7 \\
$\quad$ Victim & 51 & 50 \\
$\quad$ Nonvictim & 16 & 7
\end{tabular}

Note: Because the analysis focuses on predicting outcomes for juveniles in year 2, the age measure reflects age at year 2 . Thus, juveniles in the 11-14 age group were ages 10-13 in year 1 , and juveniles in the 15-17 age group were ages 14-16 in year 1 . 


\section{Table 5: Relationship Between Violent Offending and Violent Victimization Across Years, by Gender}

Year 2

\begin{tabular}{lcc} 
& \multicolumn{2}{c}{ Year 2 } \\
\cline { 2 - 3 } Status in Year 1 & Violent Offending (\%) & Violent Victimization (\%) \\
\hline Males & 30 & \\
All $(n=2,402)$ & 48 & 22 \\
$\quad$ Offender & 14 & 32 \\
Nonoffender & 56 & 9 \\
Victim & 23 & 51 \\
Nonvictim & & 11 \\
Females & 15 & 19 \\
All (n=2,601) & 38 & 20 \\
Offender & 7 & 4 \\
Nonoffender & 44 & 5 \\
$\quad$ Victim & 12 & 9 \\
$\quad$ Nonvictim & &
\end{tabular}

\section{Table 6: Relationship Between Violent Offending and Violent Victimization Across Years, by Race}

\begin{tabular}{lcc} 
& \multicolumn{2}{c}{ Year 2 } \\
\cline { 2 - 3 } Status in Year 1 & Violent Offending (\%) & Violent Victimization (\%) \\
\hline Minority juveniles & 25 & 20 \\
All $(n=2,235)$ & 42 & 32 \\
$\quad$ Offender & 13 & 12 \\
$\quad$ Nonoffender & 50 & 53 \\
$\quad$ Victim & 20 & 11 \\
$\quad$ Nonvictim & & \\
White juveniles & 21 & 12 \\
All (n=2,768) & 45 & 25 \\
$\quad$ Offender & 9 & 4 \\
$\quad$ Nonoffender & 54 & 43 \\
$\quad$ Victim & 16 & 6 \\
$\quad$ Nonvictim & &
\end{tabular}

whites, juveniles who offended in year 1 were significantly more likely than nonoffenders to be victimized in year 2 and to offend in year 2, and juveniles who were victimized in year 1 were significantly more likely than nonvictims to offend in year 2 and to be victimized in year 2. Again, these findings are consistent with the pattern for all juveniles.

\section{For males:}

* How much hair is under your arms?

* How thick is the hair on your face?

* How much lower is your voice than when you were in grade school?

* How advanced is your physical development compared to other boys your age?

- For females:

* How much more developed are your breasts than when you were in grade school?

* How much more curvy is your body compared to when you were in grade school?

* How advanced is your physical development compared to other girls your age?

As shown in table 7, the total percentage of juveniles who committed a violent offense in year 2 and the total percentage who were victims of violence in year 2 were significantly greater for more physically developed juveniles. For both groups, juveniles who offended in year 1 were significantly more likely than nonoffenders to be victimized in year 2, and those who were victimized in year 2 were significantly more likely than nonvictims to offend in year 2. Again, these findings are consistent with the pattern for all juveniles.

\section{Effects of Drug Use}

Drug use and its influence on the relationship between violent victimization and offending were also examined. In both years, the percentage of juveniles reporting drug use was significantly greater among juveniles ages 15-17 than juveniles ages 11-14 but was not significantly different for males and females or for minorities and whites. To determine the influence of drug use on the relationship between victimization and offending, multivariate analysis was performed within each of the four drug use categories defined on page 3 : nonusers $(n=3,270)$; desisters $(n=481)$, new users $(n=455)$, and consistent users $(n=797)$. In general, drug use did not influence the victimization-offending relationship: violent victimization increased the risk of violent offending and violent offending increased the risk of violent victimization, regardless of drug use. ${ }^{10}$ 


\section{Table 7: Relationship Between Violent Offending and Violent Victimization} Across Years, by Level of Physical Development

\begin{tabular}{|c|c|c|}
\hline \multirow[b]{2}{*}{ Status in Year 1} & \multicolumn{2}{|c|}{ Year 2} \\
\hline & Violent Offending (\%) & Violent Victimization (\%) \\
\hline \multicolumn{3}{|c|}{$\begin{array}{l}\text { More physically } \\
\text { developed juveniles }\end{array}$} \\
\hline All $(n=2,449)$ & 25 & 17 \\
\hline $\begin{array}{l}\text { Offender } \\
\text { Nonoffender }\end{array}$ & $\begin{array}{l}50 \\
10\end{array}$ & $\begin{array}{r}32 \\
7\end{array}$ \\
\hline $\begin{array}{l}\text { Victim } \\
\text { Nonvictim }\end{array}$ & $\begin{array}{l}57 \\
19\end{array}$ & $\begin{array}{r}52 \\
8\end{array}$ \\
\hline \multicolumn{3}{|c|}{$\begin{array}{l}\text { Less physically } \\
\text { developed juveniles }\end{array}$} \\
\hline All $(n=2,554)$ & 20 & 13 \\
\hline $\begin{array}{l}\text { Offender } \\
\text { Nonoffender }\end{array}$ & $\begin{array}{r}38 \\
9\end{array}$ & $\begin{array}{r}25 \\
4\end{array}$ \\
\hline $\begin{array}{l}\text { Victim } \\
\text { Nonvictim }\end{array}$ & $\begin{array}{l}47 \\
15\end{array}$ & $\begin{array}{r}42 \\
7\end{array}$ \\
\hline
\end{tabular}

\section{Table 8: Factors Predicting Violent Offending in Year 2}

\begin{tabular}{lcc} 
Predictor* $^{*}$ & Logistic Coefficient & Odds Ratio $^{\dagger}$ \\
\hline Violent offending in year 1 & $1.39(.09)$ & 4.01 \\
Violent victimization in year 1 & $0.86(.11)$ & 2.36 \\
Male & $0.71(.11)$ & 2.03 \\
Consistent drug user & $0.62(.16)$ & 1.86 \\
New alcohol user & $0.59(.15)$ & 1.80 \\
Consistent alcohol user & $0.56(.13)$ & 1.75 \\
New drug user & $0.36(.17)$ & 1.43 \\
More physically developed & $0.30(.10)$ & 1.35 \\
Depression & $0.23(.11)$ & 1.26 \\
Support from significant others & $-0.26(.09)$ & 0.77 \\
Household socioeconomic status & $-0.19(.06)$ & 0.83
\end{tabular}

Note: See sidebar on page 8 for methodological notes.

* Only significant $(p<.05)$ predictors are reported here. The sidebar on page 8 includes a complete list of the variables analyzed.

† The logistic coefficient represents the effect of a given predictor variable (e.g., violent offending in year 1) on the log odds of the outcome (i.e., violent offending in year 2). Positive numbers indicate risk factors; negative numbers indicate protective factors. Standard errors are in parentheses.

* The odds ratio indicates the proportional change in the odds of violent offending in year 2, per one-unit increase in the predictor variable. The greater the difference from one, the greater the effect of the variable on violent offending.

\section{Risk and Protective Factors}

Multivariate analyses were also used to identify risk and protective factors for violent offending and victimization (i.e., factors that independently predict offending or victimization in year 2 after statistical controls for other factors are introduced into the model). Tables 8 and 9 present the results of the analyses, and the sidebar on page 8 discusses the methodology used in the analyses.

Violent offending. The results presented in table 8 indicate that, even after other factors related to violent offending were controlled statistically, being a victim of a violent crime in year 1 was still a significant risk factor for committing a violent offense in year 2. Only violent offending in year 1 had a greater influence. The analysis also revealed an important protective factor against violent offending in year 2 : juveniles who reported greater support from important people in their lives, such as friends, parents, and teachers, were less likely to commit a violent offense in year 2 .

Violent victimization. The results presented in table 9 indicate that, when all other risk factors were controlled statistically, committing a violent offense in year 1 was still a significant risk factor for being the victim of a violent crime in year 2 . Only the effects of violent victimization in year 1 , being male, being a consistent drug user, and being a new drug user had a greater influence. Finally, violent victimization was significantly less likely among white juveniles than among minority juveniles, ${ }^{11}$ among juveniles who resided in two-parent households than among those with other family structures, and among juveniles who resided in households with higher socioeconomic status than among those with lower socioeconomic status.

\section{Conclusions}

The analyses suggest three major conclusions:

Violent victimization is an important risk factor for subsequent violent offending. The percentage of year 1 victims who committed a violent offense in year 2 (52 percent) was significantly higher than the percentage of year 1 nonvictims who committed a violent offense in year 2 (17 percent). The figure on page 7 (which reflects the percentages in table 3 ) illustrates this finding. 


\section{Table 9: Factors Predicting Violent Victimization in Year 2}

\begin{tabular}{|c|c|c|}
\hline Predictor* & Logistic Coefficient ${ }^{\dagger}$ & Odds Ratio ${ }^{\ddagger}$ \\
\hline Violent victimization in year 1 & $1.74(.13)$ & 5.70 \\
\hline Male & $0.91(.13)$ & 2.48 \\
\hline Consistent drug user & $0.85(.18)$ & 2.34 \\
\hline New drug user & $0.77(.19)$ & 2.16 \\
\hline Violent offending in year 1 & $0.69(.12)$ & 1.99 \\
\hline Depression & $0.52(.12)$ & 1.68 \\
\hline Consistent alcohol user & $0.47(.16)$ & 1.60 \\
\hline Easy access to gun in home & $0.40(.16)$ & 1.49 \\
\hline More physically developed & $0.29(.13)$ & 1.34 \\
\hline Time spent hanging out with friends & $0.17(.06)$ & 1.19 \\
\hline White & $-0.53(.14)$ & 0.59 \\
\hline Two-parent household & $-0.43(.13)$ & 0.65 \\
\hline Household socioeconomic status & $-0.23(.07)$ & 0.79 \\
\hline
\end{tabular}

Note: See sidebar on page 8 for methodological notes.

* Only significant $(p<.05)$ predictors are reported here. The sidebar on page 8 includes a complete list of the variables analyzed.

$\uparrow$ The logistic coefficient represents the effect of a given predictor variable (e.g., violent victimization in year 1 ) on the log odds of the outcome (i.e., violent victimization in year 2). Positive numbers indicate risk factors; negative numbers indicate protective factors. Standard errors are in parentheses.

* The odds ratio indicates the proportional change in the odds of violent victimization in year 2, per one-unit increase in the predictor variable. The greater the difference from one, the greater the effect of the variable on violent victimization.

\section{Percentage of Juveniles Who Offended or Were Victimized in Year 2, by Status in Year 1}

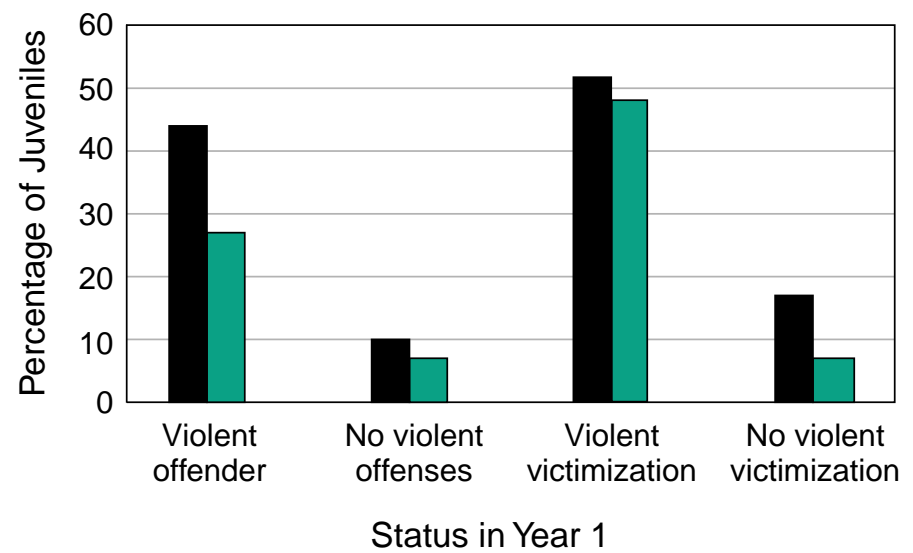

Violent offending in year 2

Violent victimization in year 2
Repeat offending is more common than repeat victimization. The relationship of violent offending in year 1 to violent offending in year 2 was stronger than the relationship of violent victimization in year 1 to violent victimization in year 2 . Approximately twice as many juveniles committed an offense in both years as were victimized in both years.

Violent victimization and violent offending share many of the same risk factors. Shared risk factors include previous violent victimization and offending, use of drugs or alcohol, being male, depression, and having a high level of physical development.

\section{Policy Implications}

The findings of this analysis have at least four policy implications:

Some groups are at higher risk than others for violent victimization. The percentage of juveniles who were victims of violent crime in this sample was high: 26 percent were victimized at least once during the 2-year study period and 9 percent were victimized at least twice. Significantly higher rates of violent victimization were found among juveniles with certain characteristics - those who used drugs consistently or began to use drugs, those who were depressed, members of racial minority groups, and older juveniles who committed violent offenses. These findings suggest that victimization prevention programs may be most effective if they are focused on these groups. Because of the strong association between drug use and victimization, drug use prevention and treatment programs might be promising strategies for decreasing juveniles' risk of violent victimization.

Violent victimization is a warning signal for future violent victimization. About one-half of the juveniles who reported being victims of violence during year 1 also reported being victimized during year 2 . These repeat victims might be especially suitable for interventions to prevent future victimization. Other research has shown that crime victims are more likely than nonvictims to experience depression, anxiety, and physical health problems (Kilpatrick et al., 1985). Studies have also shown that the greater the severity of the victimization (e.g., a higher level of violence), the more severe the symptoms (Bard and Sangrey, 1985; Riggs, Rothbaum, and Foa, 1995). The current study found 
that the higher the level of juveniles' depression, the greater their likelihood of becoming victims of violence. This finding suggests that focusing counseling and other victim services on juvenile victims of violent crime-especially repeat victimsmay be particularly important.

Violent victimization is a warning signal for future violent offending. The finding that being a victim of a violent crime predicted violent offending suggests that victimization is itself a risk factor for offending or is correlated with some factor or process that is a risk factor. This implication, in turn, suggests that protecting juveniles against violent victimization may reduce overall levels of juvenile violence. Because juveniles are probably more likely to admit victimization than offending, interventions focused on victims might be easier to accomplish than interventions focused on offenders. The finding that the effect of violent victimization on offending appears to be stronger within years than across years (see tables 2 and 3 ) suggests that interventions may be most successful in preventing future offending if they are applied relatively soon after the victimization.

Many of the risk factors associated with juvenile violence suggest opportunities for intervention. A number of the risk factors presented in tables 8 and 9 involve the behavior of juveniles and people who are important in their lives; as such, these factors are appropriate points for intervention. Because the majority of risk factors predicted both violent offending and violent victimization, it may be possible for interventions to simultaneously reduce juveniles' risk of both.

\section{Future Research}

This study suggests several areas for future research:

The links by which offending and victimization affect each other should be explored. The findings of this study suggest both that offending increases juveniles' risk of victimization and that victimization increases juveniles' risk of offending. Future research should examine links that might explain these two processes. For example, being victimized might increase juveniles' use of drugs, and drug use might make them more vulnerable to victimization because they are less able to protect

\section{Methodology for Analyses of Risk and Protective Factors}

The multivariate analyses of risk and protective factors used cross-lag logistic regression techniques. For each outcome variable at year 2, the statistical model included a term controlling for the effect of that variable at year 1 . For example, the model predicting the log odds of being a violent offender in year 2 included a control for status as a violent offender in year 1. For reasons similar to those explained in endnote 10, the results of multivariate analyses presented in tables 8 and 9 are based on models that excluded all interaction terms for age, gender, and race.

The multivariate analyses of victimization and offending in year 2 included the following independent variables: time spent hanging out with friends; drug use; alcohol use; tobacco use; race; depression (a standardized, composite index reflecting juveniles' mean score on 14 psychosomatic symptoms and 5 emotional symptoms commonly associated with depression); support from others (a standardized, composite index of 7 items reflecting juveniles' perceptions of how much adults, friends, and teachers care about them); age (in years); age squared; easy access to a firearm in the home; whether the juvenile lived in a home with two parental figures during both years; and household socioeconomic status (a standardized mean of parental occupational prestige and parental education). Variables that were not significant predictors are excluded from tables 8 and 9.

The models predicting victimization in year 2 included controls for juveniles' property offending and minor deviance and delinquency. This was done to ensure that the observed effects of violent offending on violent victimization reflected only the effect of violence and not the tendency of juveniles who commit violent crimes to also commit property crimes and to be involved in other delinquent and deviant activities. The measure of property offending was a dichotomous variable based on six activities reflecting involvement in property offending. The measure of minor deviance and delinquency was also a dichotomous variable and was based on five activities reflecting involvement in minor crimes (e.g., disorderly conduct) and status offenses (e.g., running away from home).

themselves. Research should also focus on the extent to which victimization affects juveniles' mental and physical health.

The role of delinquent peers should be investigated. Because in most crimes the victim and the offender know each other, association with delinquent peers may explain not only juveniles' offending (Hawkins et al., 2000) but also their victimization. Previous research suggests that some of the relationship between offending and victimization and between victimization and offending is explained by the delinquency of juveniles' peers (Lauritsen, Sampson, and Laub, 1991; Fagan, Piper, and Cheng, 1987). However, the effect of peers has not been isolated from the effects of juveniles' own prior offending and victimization. A related finding of the present study-that time spent in unstructured activity with peers (i.e, "hanging out with friends") was a significant risk factor for violent victimizationoffers some evidence to support victimization theories based on routine activities and lifestyle exposure. Future research should provide more rigorous tests of measures of routine activities to explain the relationship between offending and victimization in juveniles.

The reciprocal nature of the relationship between victimization and offending needs clarification. The present study found some evidence that the relationships between victimization and offending in juveniles may be more simultaneous than the cross-year relationships that were the focus of the study. Future research should explore the possibility that violent victimization and offending may have stronger short-term than long-term influences on each other.

\section{For Further Information}

To obtain data files from the National Longitudinal Study of Adolescent Health, contact Jo Jones, Carolina Population Center, 123 West Franklin Street, Chapel Hill, NC 27516-3997 (e-mail jo_jones@unc.edu). 


\section{Endnotes}

1. The Add Health Study is being conducted by the Carolina Population Center at the University of North Carolina at Chapel Hill under a grant from the National Institute of Child Health and Human Development. Approval to use the data was granted by the Carolina Population Center, the Population Research Institute at Pennsylvania State University, and the Pennsylvania State University Institutional Review Board.

2. In the Add Health Study, clusters were sampled with unequal probability. Although this method reduced the costs of data collection, the design complicated the statistical analysis because the observations were not independent and identically distributed. Correct analysis of the data requires the use of special survey software packages capable of handling observations that are not independent and not identically distributed (Chantala and Tabor, 1999).

3 . The minority racial category (about 45 percent of the sample) includes the following groups: African Americans (22 percent of the sample); Asians (6 percent), American Indians (2 percent), Hispanic whites (7 percent), and other racial or ethnic groups (8 percent).

4. For a large group of respondents, the second interview took place less than 12 months after the initial interview. Because the majority of the measures used in the analyses asked respondents about "the last 12 months," those whose second interview took place less than 11 months after the initial interview were excluded from the analyses.

5. Some households had more than one child represented in the sample. To eliminate the bias that would otherwise result from the fact that responses from children within the same household were correlated, only the youngest child in each household was included in the analyses. If a household had two children of the same age, one was randomly selected for the analyses.

6. All of the analyses and statistical tests for this Bulletin were conducted using the survey estimation procedures in Stata Release 7, a publicly available statistical package capable of handling complex survey designs such as that of the Add Health Study.
7. The response alternatives for offending and victimization were "never," "once," and "more than once." For the analyses presented here, these responses were recoded to "yes" (once or more than once) or "no" (never). It is important to keep in mind that most of the measures discussed in this Bulletin necessarily rely on the willingness and accuracy of the juvenile respondents' self-reports. Analyses of the National Crime Victimization Survey (NCVS) indicate that juveniles are less likely than adults to report violent victimization to the police, although juveniles and adults are equally likely to report theft offenses (Finkelhor and Ormrod, 1999). In addition, the Add Health Study interview did not include the special rapport-building and screener questions currently used in the NCVS to capture violent crimes against women. Finally, the Add Health Study survey instrument did not specifically ask juveniles about victimization in the home (e.g., child abuse) or about property victimization.

8. In this study, telescoping could have occurred only for year 1 , because the information for year 2 was bounded by the interview for year 1 . In the first interview, even though respondents were asked about events that occurred during the prior 12 months, they might have reported events that occurred before that period. Examination of research with the NCVS data has suggested that victimization rates were higher for unbounded interviewees (those who were not interviewed 6 months earlier) than for bounded interviewees (those who were interviewed 6 months earlier) (Murphy and Cowan, 1982).

9. The physical development criteria listed on page 5 were standardized, used to create separate scales for males and females, and then recombined into a single scale. Juveniles who scored in the 50th percentile or higher were coded as more physically developed, and those who scored below the 50th percentile were coded as less physically developed.

10 . The analysis of relationships between violent offending and victimization for the four categories of drug use also explored variations by age, gender, and race. Saturated models, which included all possible interactions between these three variables and offending and victimization, were tested. The number of significant interactions was smaller than would be expected to occur by chance, and the few significant interactions had no clear pattern within or across the categories of drug use. Moreover, within the specific distribution cells (e.g., female consistent drug users), the sample sizes were quite small, resulting in less stable estimates and lower statistical power for detecting significant effects. Thus, the results presented here are based on models that excluded all interaction terms.

11. In the analyses of risk and protective factors for both offending and victimization, it is important to interpret findings regarding juveniles' race cautiously. The analyses presented here did not include controls for juveniles' neighborhoods, and it is possible that the observed effects for race would be reduced, or even disappear, if adequate controls for neighborhood type were included in the model.

\section{References}

Bard, M., and Sangrey, D. 1986. The Crime Victim's Book, 2nd ed. New York, NY: Bruner/Mazel Publishers.

Chantala, K., and Tabor, J. 1999. Strategies To Perform a Design-Based Analysis Using the Add Health Data. Chapel Hill, NC: Carolina Population Center, University of North Carolina at Chapel Hill. Copies may be viewed or printed at www.cpc.unc.edu/ projects/addhealth/strategies.html.

Cohen, L.E., and Felson, M. 1979. Social change and crime rate trends: A routine activity approach. American Sociological Review 44(4):588-609.

Elliott, D.S., Ageton, S.S., Huizinga, D., Knowles, B.A., and Cantor, R.J. 1983. The Prevalence and Incidence of Delinquent Behavior: 1976-1980: National Estimates of Delinquent Behavior by Sex, Race, Social Class, and Other Selected Variables. Boulder, CO: Behavioral Research Institute.

Esbensen, F., and Huizinga, D. 1991. Juvenile victimization and delinquency. Youth \& Society 22(2):202-228. 
Fagan, J., Piper, E.S., and Cheng, Y. 1987. Contributions of victimization to delinquency in inner cities. Journal of Criminal Law and Criminology 78(3):586-609.

Federal Bureau of Investigation. 2000. Crime in the United States 1999. Washington, DC: U.S. Government Printing Office.

Finkelhor, D., and Ormrod, R. 1999. Reporting Crimes Against Juveniles. Bulletin. Washington, DC: U.S. Department of Justice, Office of Justice Programs, Office of Juvenile Justice and Delinquency Prevention.

Hawkins, J.D., Herrenkohl, T.I., Farrington, D.P., Brewer, D., Catalano, R.F., Harachi, T.W., and Cothern, L. 2000. Predictors of Youth Violence. Bulletin. Washington, DC: U.S. Department of Justice, Office of Justice Programs, Office of Juvenile Justice and Delinquency Prevention.

Hindelang, M.J. 1981. Variations in sexrace-age-specific incidence rates of offending. American Sociological Review 46(4): 461-474.

Hindelang, M.J., Gottfredson, M.R., and Garofalo, J. 1978. Victims of Personal Crime: An Empirical Foundation for a Theory of Personal Victimization. Cambridge, MA: Ballinger.

Hough, M., and Mayhew, P. 1983. The British Crime Survey: First Report. London, England: Her Majesty's Stationery Office.

Jensen, G.F., and Brownfield, D. 1986. Gender, lifestyles, and victimization: Beyond routine activity. Violence and Victims 1(2): 85-99.
Johnston, L.D., Bachman, J.G., and O'Malley, P.M. 2001. Monitoring the Future: Questionnaire Responses From the Nation's High School Seniors, 1998. Ann Arbor, MI: Institute for Social Research, University of Michigan.

Kilpatrick, D., Best, C., Veronen, L., Amick, A., Villeponteaux, L., and Ruff, G. 1985. Mental health correlates of criminal victimization: A random community survey. Journal of Consulting and Clinical Psychology 53(6):866-873.

Lauritsen, J.L., Sampson, R.J., and Laub, J.H. 1991. The link between offending and victimization among adolescents. Criminology 29(2):265-292.

Murphy, L.R., and Cowan, C.D. 1982. Effects of bounding on telescoping in the National Crime Survey. In The National Crime Survey: Working Papers, vol. II: Methodological Studies, edited by R.G. Lehner and W.G. Skogan, Washington, DC: U.S. Department of Justice, Office of Justice Programs, Bureau of Justice Statistics, pp. 83-89.

Riggs, D., Rothbaum, B., and Foa, F. 1995. A prospective examination of symptoms of posttraumatic stress disorder in victims of nonsexual assault. Journal of Interpersonal Violence 10(4):201-214.

Sampson, R.J., and Lauritsen, J.L. 1990. Deviant lifestyles, proximity to crime, and the offender-victim link in personal violence. Journal of Research in Crime and Delinquency 27(2):110-139.
Sampson, R.J., and Lauritsen, J.L. 1994. Violent victimization and offending: Individual-, situational-, and communitylevel risk factors. In Understanding and Preventing Violence, vol. 3, edited by A.J. Reiss and J.A. Roth. Washington, DC: National Academy Press, pp. 1-114.

Snyder, H.N., and Sickmund, M. 1999. Juvenile Offenders and Victims: 1999 National Report. Washington, DC: U.S. Department of Justice, Office of Justice Programs, Office of Juvenile Justice and Delinquency Prevention.

Sparks, R. 1982. Research on Victims of Crime. Washington, DC: U.S. Government Printing Office.

Preparation of this Bulletin was funded by the National Center for Juvenile Justice's National Juvenile Justice Data Analysis Project, which is supported by cooperative agreement number 99-JN-FX-K002 with the Office of Juvenile Justice and Delinquency Prevention, Office of Justice Programs, U.S. Department of Justice.

The Office of Juvenile Justice and Delinquency Prevention is a component of the Office of Justice Programs, which also includes the Bureau of Justice Assistance, the Bureau of Justice Statistics, the National Institute of Justice, and the Office for Victims of Crime. 


\section{Acknowledgments}

Jennifer N. Shaffer is a doctoral candidate at the Pennsylvania State University and a predoctoral fellow at the National Consortium on Violence Research. R. Barry Ruback is Professor of Crime, Law, and Justice and Sociology at the Pennsylvania State University.

This research is based on data from the Add Health project, a program designed by J. Richard Udry (principal investigator) and Peter Bearman and funded by grant P01-HD31921 from the National Institute of Child Health and Human Development to the Carolina Population Center, University of North Carolina at Chape Hill, with cooperative funding participation by the National Cancer Institute; the National Institute of Alcohol Abuse and Alcoholism; the National Institute of General Medical Sciences; the National Institute of Mental Health; the National Institute of Nursing Research; the Office of AIDS Research, National Institutes of Health $(\mathrm{NIH})$; the Office of Behavior and Social Science Research, NIH; the Office of the Director, NIH; the Office of Research on Women's Health, $\mathrm{NIH}$; the Office of Population Affairs, U.S. Department of Health and Human Services (HHS); the National Center for Health Statistics, Centers for Disease Control and Prevention, HHS; the Office of Minority Health, Centers for Disease Control and Prevention, HHS; the Office of Minority Health, Office of the Assistant Secretary for Health, HHS; the Office of the Assistant Secretary for Planning and Evaluation, HHS; and the $\mathrm{Na}$ tional Science Foundation.

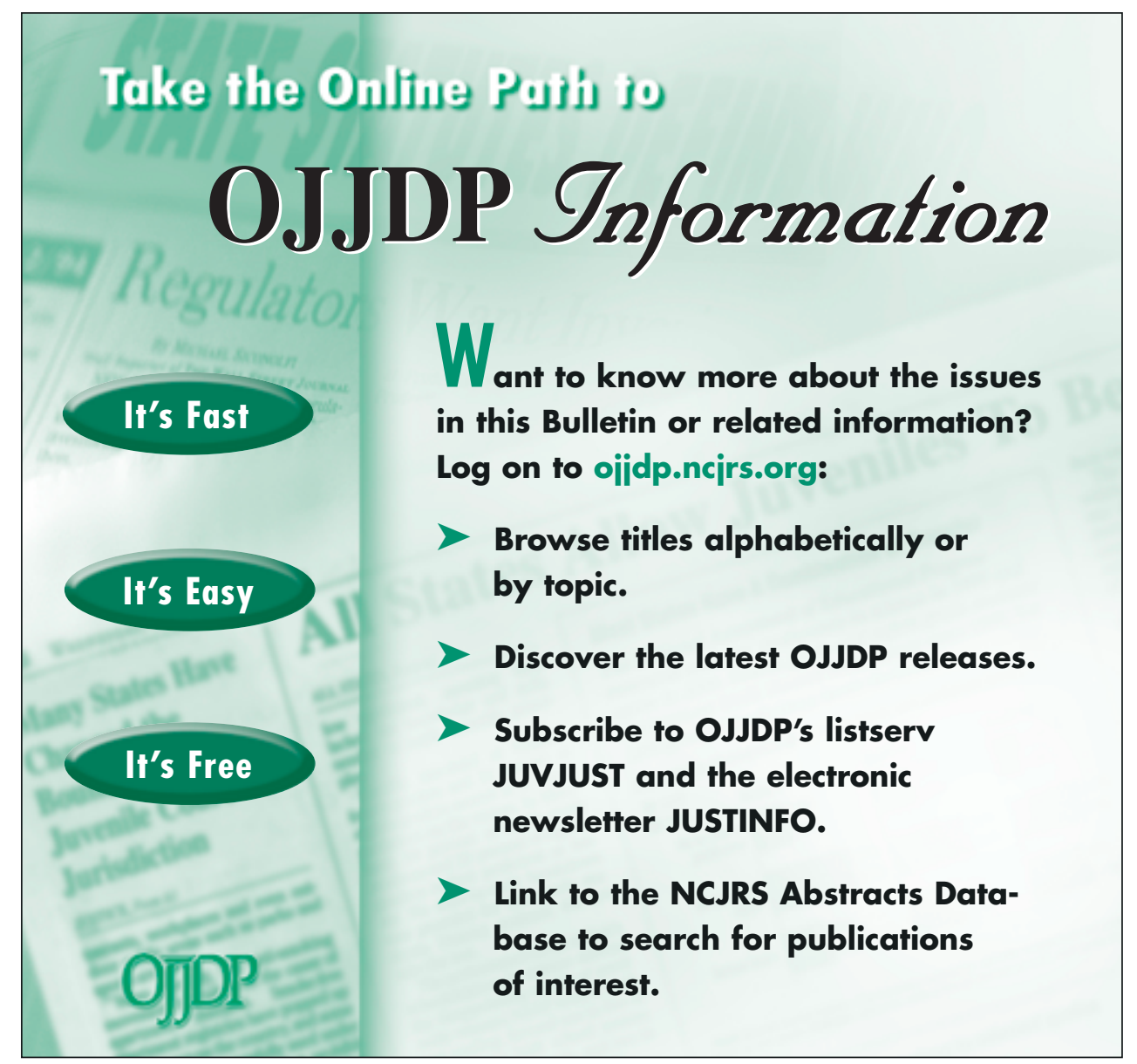

\section{Share With Your Colleagues}

Unless otherwise noted, OJJDP publications are not copyright protected. We encourage you to reproduce this document, share it with your colleagues, and reprint it in your newsletter or journal. However, if you reprint, please cite OJJDP and the authors of this Bulletin. We are also interested in your feedback, such as how you received a copy, how you intend to use the information, and how OJJDP materials meet your individual or agency needs. Please direct your comments and questions to: 
U.S. Department of Justice

Office of Justice Programs

Office of Juvenile Justice and Delinquency Prevention

Washington, DC 20531

Official Business

Penalty for Private Use $\$ 300$
PRESORTED STANDARD POSTAGE \& FEES PAID DOJ/OJJDP PERMIT NO. G-91 